\title{
MOBILE AND WEB BASED REMOTE BUSINESS MONITORING SYSTEM
}

\author{
Boniface Ndau Mutinda ${ }^{1}$, Karari Ephantus Kinyanjui ${ }^{2}$ Kihuha Cyrus kamau $^{3}$ \\ ${ }^{1}$ Department of Computer Science, Dedan Kimathi University of Technology, Nyeri, \\ Kenya \\ bonifacedibearesearch.org \\ ${ }^{2}$ Department of Computer Science, Dedan Kimathi University of Technology, Nyeri, \\ Kenya \\ efantus.kinyanjui@dkut.ac.ke \\ ${ }^{2}$ Department of Computer Science, Dedan Kimathi University of Technology, Nyeri, \\ Kenya \\ cyrus.kamau@dkut.ac.ke
}

\begin{abstract}
The adoption of contemporary information technology by businesses in Kenya and East Africa is on the rise. This is especially due to the fall in price of hardware and the availability of affordable software. Some businesses have adopted stand alone systems for purposes of enhancing the operational efficiency of their branches. An affordable tool that would monitor the activities of each branch remotely and provide information to the manager( $s)$ is required. With availability of smart phones and tablets, its only better that such a tool provides a mobile interface so that the monitoring can be done on the go.
\end{abstract}

This paper is a summary of a research project carried out to fulfil this need. The product of this research is an application that uses simulation techniques to manipulate the data collected via the internet from various remote branches and provide reports in textual and graphical formats.

\section{KEYWORDS}

Business Activity monitoring, Complex event processing, MPesa, Dashboard

\section{INTRODUCTION}

The fall in price of computer hardware has resulted to increased automation of business in many parts of the world, Kenya and the larger East Africa region been one of them.In fact , it said phones and specifically smart phones/tablets could be spreading than any other technology in human history[1].

The adoption of distributed computing solutions for point of sale and inventory management has not solved the challenge of interlinking branches of the same store and providing real time data on the performance to the management. The later is a concept Gartner Research refers to as Business Activity Monitoring (BAM) [2] and is a key factor in enhancing speed and agility [3] which is relevant for any business that wants to remain competitive in today's information age. 
International Journal of Advanced Information Technology (IJAIT) Vol. 3, No. 4, August 2013

BAM provides a better solution than calling and requesting for reports in emails a common practice in Kenya and the larger east Africa especially for micro, small and medium enterprises. In a number of instances, the branch managers have betrayed the trust by getting involved in fraud and relaying erroneous information to the regional managers or managers at the organization's headquarters as has happened with some Savings and Credit Cooperatives (SACCO) [4].

Remote Business monitoring System is formulated alongside the same concept as BAM but with a focus to affordability and platform independence, these two will take care of the main challenges faced by micro, small and medium enterprises in adopting this technology in their existing systems. It is clear BAM is undoubtedly the next frontier of business systems solution for reasons to do with enhancing both operational efficiency and quality of information used by managers in decision making [3]. The end result of having affordable business monitoring software for a distributed store is to catapult such organizations expansion strategies, enhance quality of information hence speed and agility.

\section{PROBLEM STATEMENT}

For businesses with branches in remote areas, the provision of quality information from the branches for purposes of enhancing operational efficiency and decision making by managers is a key challenge.

Quality of information as mentioned here provides for the three dimensions; content, time and form dimension. From a content dimension information is expected to be accurate, relevant and complete. Form a time dimension information should be timely and current (up to date) and from a form dimension it should be clear, orderly and presented in the most appropriate format; say video, audio or textual depending on its nature.

The challenge mentioned above is coupled with the need for the solution to be cost effective as to make economic sense to micro, small and medium enterprises (SMEs) such as mobile money transfer (MPesa) outlets and boutiques. Affordability was key for this project.

\section{OBJECTIVES}

The main aim of the project is to develop a system that can provide micro, small and medium enterprises owners/managers with real time remote business monitoring via both personal computer and tablets at an affordable price. Other project objectives are:

i. Generate real time business updates

ii. Generate business operations' reports

iii. To enhance report sharing.

iv. Minimize the costs incurred in managing the business

v. Enhance affordability of BAM tools to micro, small and medium enterprise by exploiting open source platform independent tools.

\section{JUSTIFICATION}

The completed solution when applied by a business will provide benefits such as:

i. Reduced costs: By making fewer or no calls and making limited or no trips to the remote branches. 
International Journal of Advanced Information Technology (IJAIT) Vol. 3, No. 4, August 2013

ii. More productivity: The time which could have been used to travel can be used to do other productive activities.

iii. Reduced Levels of Uncertainty: to some extent reports generated by business employees might contain errors and omissions. Making use of a remote business monitoring systems would reduce such incidences since the data is kept away from employee's interference in a password secured database.

\section{GENERAL SCOPE AND APPLICATION OF THE PROJECT}

The product of this project can be applied by micro, small and medium enterprises in Kenya and other parts of the world. It is designed for businesses with several branches that require real time business monitoring such as supermarkets, Savings and Credit Co-operative Societies (SACCOs) and mobile payment solutions (MPesa) outlets.

\section{LITELATURE REVIEW}

The research conducted in this project revealed that there is no specific platform deployed to monitor business for the SMEs in Kenya. However, a number of solutions have been developed for automating the process of monitoring business activities elsewhere and are discussed below:

\subsection{SpectorSoft SMB solutions}

SpectorSoft[5] in addition to supplies of monitoring tools, have developed an Internet monitoring and surveillance product for business, education, government and general home users which does not necessarily target a specific user category. Their mode of monitoring is also very costly since they rely on cameras to track user activities. This product is not suitable for provision of information in support of several managerial functions.

\subsection{Workexaminer}

Workexaminer[6] is software that is used to monitor employee's activities by keeping track of what he/she is or has been doing on a machine ranging from the programs accessed, how long has he spent and generate timely reports based on these activities.

The information that is also available includes:

i. How long the user has accessed the internet

ii. Which websites has the user accessed and the time spent on each site

iii. Screen snapshot widget- get a snapshot of a user desktop at a specific time

The software's mentioned above is limited to employee and hence not suitable for several managerial functions.

\subsection{Internet monitoring software}

Employee internet monitoring software tells you everything your employees are doing online during the working hours. It provides answers to questions facing the employers, or managers in the corporate sector every day. You can get this information at any moment in real time or by a schedule. It's also possible to restrict access to the internet by setting up a list of "allowed" websites and time slots within which these URLs can be visited. However, this software is very 
International Journal of Advanced Information Technology (IJAIT) Vol. 3, No. 4, August 2013

costly and does not necessarily target a specific user category. Therefore, it is not suitable for provision of information in support most managerial functions

\subsection{Apama DashBoard studio}

Apama Dashboard Studio is part of Progress ${ }^{\circledR}$ Apama ${ }^{\circledR}$ Event Processing Platform. The studio offers a richly-featured business activity monitoring dashboard design and execution environment. With up-to-the-second visualizations of key metrics driving event-driven operations, Dashboard Studio gives decision-makers the ability to see operational activity in real time and generate alerts when conditions are detected that warrant action.

Apama Dashboard Studio is designed with a wide variety of visual objects for intuitive monitoring, including meters, tables, grids, scales, bar and pie charts, as well as trend and XY charts. All can be connected to the underlying Apama complex event processing engine so that they change dynamically as business events occur in real time. Users can customize the dashboard with a design palette, placing objects on a visual canvas and defining parameters. Users have the ability to view sophisticated summary configurations while simultaneously drilling down for a more granular view.[7]

The key elements of the Apama BAM architecture extend beyond dashboards to include [7]:

1. RAD Dashboard Development Tools - The Apama platform features a flexible development environment that allows rapid application development (RAD) of dashboards.

2. CEP Engine - The Apama Event Correlator monitors event streams, detecting patterns and relationships amongst the events through application of complex event processing (CEP) rules.

3. RAD CEP Development Tools - Apama's sophisticated pattern detection rules are accessible via development tools for business users, business analysts, and IT developers

4. Encapsulated Functionality - Apama incorporates unique SmartBlocks that encapsulate CEP rules and expose them to business users via a high-level functional interface.

5. Data Source and Sink Adapters - Apama can receive data from and send data to a wide variety of sources making it appropriate for a range of use cases in many markets.

6. Event Data Management, Research, Testing, and Simulation - The data that business activity monitoring solutions monitor requires a unique class of data management to capture each event, together with filtered subsets of events determined by CEP logic, and newly created "complex" events. Event data management services from Apama EventStore and Research Studio provide the basis for research, testing, and simulation.

\section{5 webMethods Optimize for B2B}

webMethods Optimize for B2B is a product of SoftwareAG which makes it possible for managers to get real-time facts about you're their supply chain, anytime. It enables the managers to make proactive decisions that improve customer satisfaction, reduce costs and protect revenue streams [8].

Used with webMethods Trading Networks, Optimize for B2B is a Business Activity Monitoring (BAM) software solution that helps you analyze and understand interactions with your trading partners. You'll gain visibility into transactions and trends across your trading network. 
International Journal of Advanced Information Technology (IJAIT) Vol. 3, No. 4, August 2013

You can define and track Key Performance Indicators (KPIs) in real-time. Find out how many orders you've received-so you can measure your success. Track percentages of late deliveries-so you can check supplier performance.

Head-off potential supply chain management issues. Optimize for B2B will automatically learn your network's normal behavior and alert you if anything unusual occurs.

The software is optimized for B2B and whereas this is necessary, the immediate concern of owners of micro and small enterprises is to obtain reports on sales, gross profits, expenditure, net profit and inventory reports. webMethods Optimize for B2B is therefore limited for other models of commerce such as $\mathrm{B} 2 \mathrm{C}$ and other basis of conducting business monitoring like mobile business intelligent[12].

\section{6 webMethods Optimize for Processes}

webMethods optimize for processes is also a product of softwareAG which gives real-time analysis on process health. It quickly identifies what's operating well and what's not. It helps the owner recognize improvement opportunities.

It gives a single view of Systems and processes which saves time and prevents service issues with a single view of your operations.

It also provides for proactive, error based alerts and yields ready to read reports. It provides for intelligent learning by monitoring each Key Performance Indicator (KPI) and learns what is "normal" based on historical patterns, such as time-of-day and day-of-month.[9]

It is a heavy tool for a micro or small organization. An alternative would have to be sought that requires fewer resources in terms of human resources and hardware and that provides a mobile interface for it.

\subsection{HP Business monitoring software}

HP Business Process Monitor (BPM) software is a synthetic monitoring solution that simulates business transactions for consistent, predictable measurement-whether or not real users are active [10]. It lets you control mobile application performance health by monitoring web and native applications as experienced from multiple devices. You can run transactions from multiple locations inside or outside your firewall. By leveraging HP LoadRunner technology, you can reuse assets in testing and production environments. And you can monitor a range of protocols and applications.

\section{8: Comparisons for remote business software}

Other software's using the BAM concept are Elite Keylogger, SoftActivity Keylogger, AceSpy Spy Software, Total Spy, PA File Sight ,Internet Security 2010,Net Nanny

System Surveillance Pro[11]

All these software provide for remote monitoring but none on how that can be done using a phone/smart phone. Some also have an affordability or a functional deficiency issue and may not be used for comprehensive performance monitoring. 
International Journal of Advanced Information Technology (IJAIT) Vol. 3, No. 4, August 2013

\section{METHODOLOGY}

\subsection{Fact finding}

Two types of data collection methods were applied in conducting this study; quantitative and qualitative methods.

Face to face interviews and observation were used as the quantitative data collection methods (primary methods) while internet research was used as qualitative data collection method.

Facts obtain from both cases indicate that the challenge of obtaining information from remote branches is real to managers. Our fact finding revealed that most managers exploit an solution which involves calling the branch supervisors and requesting reports from them which are sent via email. Even the much publicised Software as a Service cloud computing solution by Safaricom is yet to take root.

\subsection{Development methodology}

The second phase of the methodology is concerned with the detailed steps followed in the development of the solution; that is, the system development life cycle (SDLC) model applied.

For this project, the Rapid Application Development (RAD) model was used. This model uses minimum planning in favour of rapid prototyping. The "planning" of the software developed using RAD is interleaved with writing the software itself. The lack of extensive pre-planning generally allows software to be written much faster, and makes it easier to change requirements.

This method of software development involves both techniques of iterative development and software prototyping.

The steps followed using this methodology includes:

i. User requirements gathering and planning which involves development of preliminary data models and business process models using structured techniques.

ii. Requirements verification through development of prototypes, eventually to refine the data and process models.

These steps are repeated iteratively until clear and sophisticated software is developed to meet the set user requirements with a technical system design

\subsection{Evaluation}

The evaluation was conducted to determine the usability of the system which was developed during this work as well as the satisfaction of the users.

Usability testing was carried out by a group of developers who were acquainted to the problem at hand. 
International Journal of Advanced Information Technology (IJAIT) Vol. 3, No. 4, August 2013

\section{SYSTEM ANALYSIS AND DESIGN}

\subsection{System requirements}

These were classified into two categories:

\subsubsection{Functional Requirements}

The functional requirements of this system are summarised as follows:

Table 1: Functional Requirements

\begin{tabular}{|l|l|l|}
\hline$\#$ & Requirement & Brief description \\
\hline 1 & Register new user & $\begin{array}{l}\text { The system should allow the administrator to register new } \\
\text { system users }\end{array}$ \\
\hline 2 & $\begin{array}{l}\text { Update profile } \\
\text { information }\end{array}$ & $\begin{array}{l}\text { The system should allow its users to update their profile } \\
\text { information }\end{array}$ \\
\hline 3 & $\begin{array}{l}\text { View profile } \\
\text { information }\end{array}$ & $\begin{array}{l}\text { The system should be capable of allowing users to view their } \\
\text { profile information }\end{array}$ \\
\hline 4 & View products & $\begin{array}{l}\text { The system should allow employees, business owners and the } \\
\text { administrator to view all their products and specific product } \\
\text { information }\end{array}$ \\
\hline 6 & $\begin{array}{l}\text { Update products } \\
\text { data }\end{array}$ & $\begin{array}{l}\text { The system should enable the administrator, business owner or } \\
\text { the employee with the update rights to modify products } \\
\text { information. }\end{array}$ \\
\hline 7 & Delete products & $\begin{array}{l}\text { Administrator, business owner and employee should be able to } \\
\text { delete various products from the system }\end{array}$ \\
\hline 9 & Add new products & $\begin{array}{l}\text { The system should both the admin and the business owner add } \\
\text { new products }\end{array}$ \\
\hline 10 & View sales & $\begin{array}{l}\text { The system should allow employees and the business owner to } \\
\text { record new product sales }\end{array}$ \\
\hline 11 & $\begin{array}{l}\text { Mhe system should allow users to view sale statistics as they are } \\
\text { recorded }\end{array}$ \\
\hline 12 & Record expenses & $\begin{array}{l}\text { The system should allow employees to record expenses as they } \\
\text { are incurred }\end{array}$ \\
\hline 14 & View expenses & $\begin{array}{l}\text { The system should allow users to view expenses statistics as } \\
\text { they are recorded }\end{array}$ \\
\hline 15 & $\begin{array}{l}\text { Modify expenses } \\
\text { information }\end{array}$ & $\begin{array}{l}\text { The system should be capable of allowing editing of the } \\
\text { recorded expenses }\end{array}$ \\
\hline 16 & View reports & $\begin{array}{l}\text { Business owner, administrator should be capable to view } \\
\text { business processes reports on demand. }\end{array}$ \\
\hline 17 & Share reports & $\begin{array}{l}\text { The system should allow business owner to share reports with } \\
\text { other employees, send via email, download pdfs, social websites } \\
\text { data sharing }\end{array}$ \\
\hline 18 & Send Messages & $\begin{array}{l}\text { All the system users should be able to send messages via email, } \\
\text { sms }\end{array}$ \\
\hline $\begin{array}{l}\text { System users should be in a position to get their messaging } \\
\text { history }\end{array}$ \\
\hline Gessages
\end{tabular}


International Journal of Advanced Information Technology (IJAIT) Vol. 3, No. 4, August 2013

\begin{tabular}{|l|l|l|}
\hline 21 & Login & $\begin{array}{l}\text { System users must be able to login to the system for better } \\
\text { interaction }\end{array}$ \\
\hline 22 & Manage users & $\begin{array}{l}\text { The system should allow the administrator to manage system } \\
\text { users }\end{array}$ \\
\hline 23 & Manage user rights & System administrator should be able to edit users rights \\
\hline 24 & $\begin{array}{l}\text { View transaction } \\
\log \end{array}$ & $\begin{array}{l}\text { Each user should be in a position to view his/her system } \\
\text { transactions history }\end{array}$ \\
\hline 25 & Search products & $\begin{array}{l}\text { During sales recording, the user should be able to search for } \\
\text { products from the data store }\end{array}$ \\
\hline
\end{tabular}

\subsubsection{Non functional}

Non-functional requirements are constraints on various attributes of system functions or tasks. This system presents the following non-functional requirements.

Table 2: Non-functional requirements

\begin{tabular}{|c|c|c|}
\hline$\#$ & Requirement & Brief description \\
\hline 1 & System usability & $\begin{array}{l}\text { - The system should be easy to use and interact with } \\
\text { - The system must provide user friendly information and } \\
\text { in user friendly way to the user } \\
\text { - The system should provide easy to figure out } \\
\text { navigational links }\end{array}$ \\
\hline 2 & $\begin{array}{l}\text { System performance/ } \\
\text { Efficiency }\end{array}$ & $\begin{array}{l}\text { - The system information processing speed should be as } \\
\text { fast as the click of button } \\
\text { - Each task should be optimized to operate at the } \\
\text { relatively the same high speed } \\
\text { - Processing of reports and graph generation should be } \\
\text { fast }\end{array}$ \\
\hline 3 & Availability & $\begin{array}{l}\text { The system should be available to all employees, admin's, } \\
\text { business owners } \\
\text { System data should be available to the specific user on } \\
\text { demand }\end{array}$ \\
\hline 4 & Security & $\begin{array}{l}\text { Each user should have a unique ID or username and } \\
\text { password in order to login to the system }\end{array}$ \\
\hline 5 & Notifications & $\begin{array}{l}\text { The system be able to provide notifications about products } \\
\text { stock levels, new messages }\end{array}$ \\
\hline
\end{tabular}

\subsection{Resources}

\subsubsection{Hardware}

A Computer set: at least Pentium IV with the following minimum specifications:
i. 10GB Hard Drive
ii. $\quad 256 \mathrm{MB}$ Main Memory (RAM)
iii. $\quad 1.8 \mathrm{GHz}$ processor speed 
International Journal of Advanced Information Technology (IJAIT) Vol. 3, No. 4, August 2013

\subsubsection{Software}

The following software resources are necessary for the preparation of this project:

i. Netbeans 6.0/ Eclipse /JCreator or any other Java IDE

ii. Java SDK (Software Development Kit)

iii. Android SDK (Software Development Kit)

iv. Notepad++ 5.7 and above

v. Macromedia Fireworks 8.0 -for graphics development

vi. jQuery.js, highcharts.js, kScrit.js - JavaScript frameworks

vii. Xampp - latest version with php 5.3.8 or above

viii. Web browser - Internet Explorer 6 and higher, Mozilla 10.0.2, Google Chrome

ix. Windows XP sp1 and above, windows 7 any edition, windows vista, Linux

x. Microsoft Word 2003 or 2007

xi. Internet Connection

\subsection{System design}

\subsubsection{Sample: Sales dashboard}

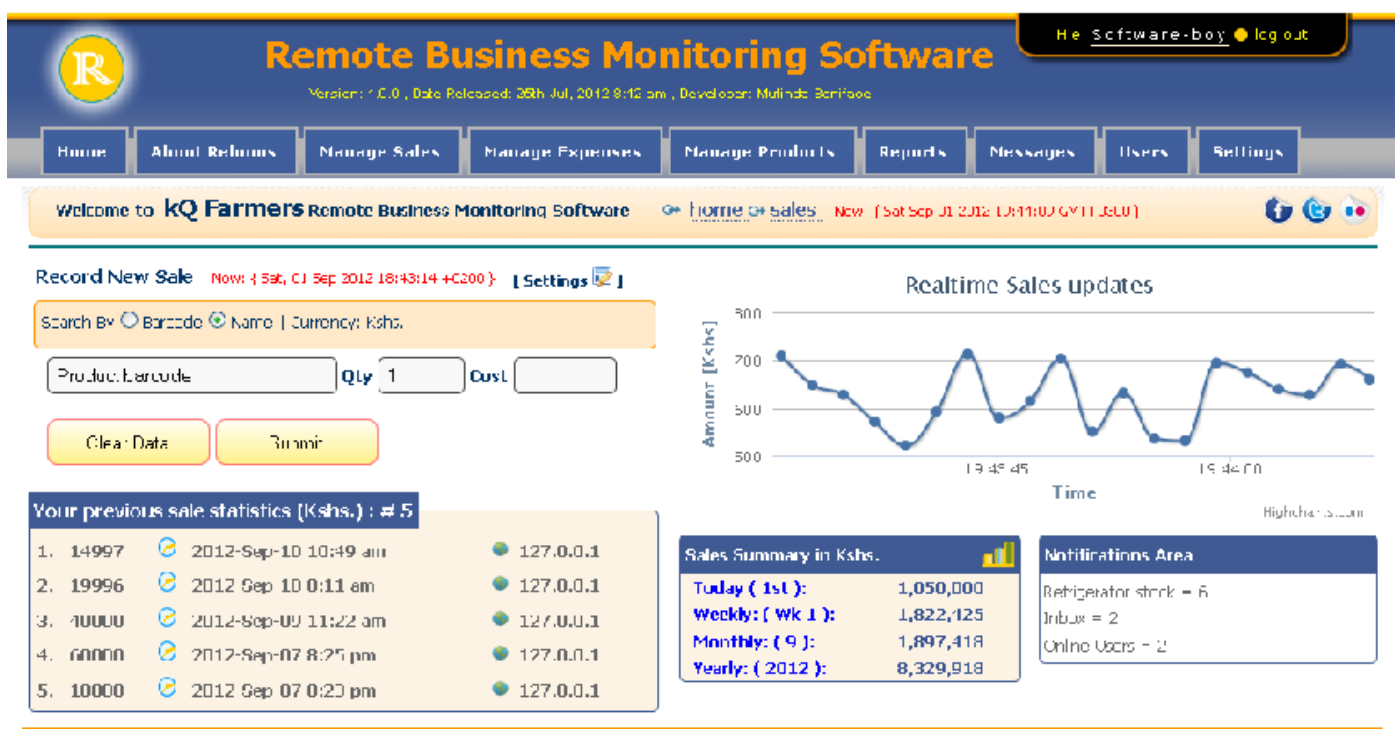

Figure 1: Sales interface

\section{Assumptions, Conclusion And Recommendations}

\subsection{Assumptions}

The following are the assumptions made throughout the whole project

i. Internet services are available

ii. Reliable hosting services are available

iii. The user has some knowledge of computer usage

iv. The business has a Point of Sale Software in place

v. The business operates in a distributed environment 
International Journal of Advanced Information Technology (IJAIT) Vol. 3, No. 4, August 2013

\subsection{Conclusion}

Remote business monitoring is in its infancy in Kenya. Some forms of monitoring of employees is already been used by software houses that use job ticketing techniques.

The rise of business monitoring is expected to accelerate due to several factors key among them cheap and reliable hardware (computers and smart phones/tablets) and internet connections.

Business monitoring will range from monitoring of all business processes to monitoring of business employees, data consistency, business processes evaluation, audit and planning of business execution processes.

Business monitoring platforms will grant a competitive advantage to those that adopt them. This research project provides a prototype for a web and mobile phone based remote business monitoring system.

\subsection{Recommendations}

We recommend further research in security features to take care of authenticity and nonrepudiation.

\section{ACKNOWLEDGEMENTS}

We very much appreciate the support accorded to us by Dedan Kimathi University of Technology. Their state of the art computer labs did not just meet but surpassed our expectations. Their students especially from the school of computer science and information technology were more than willing to participate in the project especially in fact finding and usability testing. For this we are grateful to the Vice Chancellor Prof P.N Kioni, the whole academic division headed by Prof. G.K Muthakia (Deputy Vice Chancellor Academic Affairs).

We also feel indebted to our families for continued support during the entire research period.

\section{REFERENCES}

[1] Smart phone spread-Smart phones, internet: http://www.technologyreview.com/news/427787/aresmart-phones-spreading-faster-than-any-technology-in-human-history/, 2012 [Jan. 24, 2013]

[2] Gartner definition of BAM Business Activity Monitoring - monitoring business activities: internet: http://www.gartner.com/resources/105500/105562/105562.pdf, 2002 [Jan. 24, 2013]

[3] BAM Architecture: More Building Blocks Than You Think - monitoring business activities , Internet; http://www.gartner.com/id=354281, 2002 [Jan 24, 2013]

[4] Harambee SACCO -business fraud, Internet: http://www.nation.co.ke/business/news/Sacco-probe-onas-more-rot-uncovered/-/1006/1641158/-/139dk1dz/-/index.html, 2012 [Jan. 24, 2013]

[5] Spectofoft -Business Activity Monitoring software, Internet: http://www.spectorsoft.com/ , [Feb. 14, 2013]

[6] Workexaminer- Business Activity Monitoring software, Internet: http://www.workexaminer.com/ ,[Feb. 14,2013]

[7] Apama DashBoard Studio- Business Activity Monitoring software, Internet: http://www.progress.com/en/business-activity-monitoring-software.html, [Feb . 14, 2013]

[8] webMethods optimized for B2B-BAM software, Internet: http://www.softwareag.com/corporate/products/wm/b2b/optimize_to_b2b/overview/default.asp optimize for B2B,[Mar.20, 2013] 
International Journal of Advanced Information Technology (IJAIT) Vol. 3, No. 4, August 2013

[9] webMethods for process- BAM software, Internet:

http://www.softwareag.com/corporate/products/wm/bpm/optimize_process/capabilities/default.asp , [Mar. 20, 2013]

[10] HP business monitoring software-BAM software, Internet: http://www8.hp.com/us/en/softwaresolutions/software.html?compURI=1174783\#.Ud7z09Iwf8o, [Mar. 20, 2013]

[11] Comparison of remote business control s/w-BAM software, Internet: http://monitoringsoftware.findthebest.com/d/d/Business, [Mar. 20, 2013]]

[12] Mobile Business Intelligence - monitor business via mobile devices, internet: http://en.wikipedia.org/wiki/Mobile_business_intelligence, 2006 [Mar. 2013]

\section{AUTHORS}

Name: Ndau Mutinda Boniface

Mobile: +254 713339 724, Interest: Software development, social media Occupation: Researcher and application deve loper, IBEA Research, www.ibeareseach.org

Name: Ephantus Kinyanjui Karari

Mobile: +254 721374 616, Interest: Web and Mobile computing

Occupation: Lecturer \& PhD Student; School of Computer Science,

DKUT (www.dkut.ac.ke), Nyeri, Kenya

Name: Kahuha Cyrus Kamau

Name: Kahuha Cyrus Kamau

Mobile: +254 722808500

Interest: Web and Mobile computing

Occupation: Lecturer, Department of Computer Science,

DKUT (www.dkut.ac.ke), Nyeri, Kenya
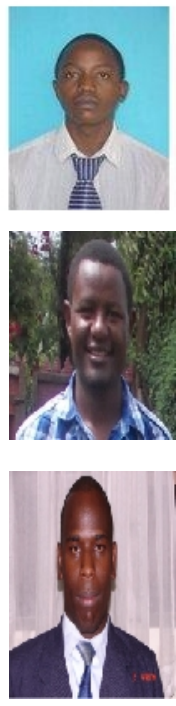